\title{
Tumor suppressor $L H P P$ regulates the proliferation of colorectal cancer cells via the PI3K/AKT pathway
}

\author{
BIN HOU ${ }^{1 *}$, WENHAN LI ${ }^{2,3 *}$, JIANHUI LI $^{2,3}$, JIA MA $^{2,3}$, PENG XIA $^{1}$, ZHAO LIU $^{1}$, \\ QINGNUO ZENG ${ }^{1}, \mathrm{XIN}_{\mathrm{ZHANG}}{ }^{1}$ and DONGMIN CHANG ${ }^{1}$ \\ ${ }^{1}$ Department of Surgical Oncology, The First Affiliated Hospital of Xi'an Jiaotong University, Xi'an, \\ Shaanxi 710061; ${ }^{2}$ Department of Surgical Oncology, Shaanxi Provincial People's Hospital, Xi'an, Shaanxi 10068; \\ ${ }^{3}$ The Third Affiliated Hospital, School of Medicine, Xi'an Jiaotong University, Xi'an, Shaanxi 710061, P.R. China
}

Received July 9, 2019; Accepted November 20, 2019

DOI: $10.3892 /$ or.2019.7442

\begin{abstract}
Colorectal cancer (CRC) is the third most commonly diagnosed cancer and the fourth leading cause of cancer-related mortality worldwide. Thus, identification of the mechanisms involved in the progression of $\mathrm{CRC}$ has become a crucial element of facilitating early CRC diagnosis and targeted therapy for patients with advanced CRC. Currently, Phospholysine phosphohistidine inorganic pyrophosphate phosphatase (LHPP), a type of histidine phosphatase protein, has been confirmed as a tumor suppressor in hepatocellular carcinoma (HCC) and cervical cancer. However, the functions and molecular mechanisms underlying $L H P P$ in CRC remain undefined. The present study revealed that dysregulation of $L H P P$ was frequently observed in CRC tissues and was positively correlated with tumor severity and poor prognosis. Functional experiments demonstrated that overexpression of LHPP impeded CRC cell growth and proliferation in vitro, and was associated with a change in p53 expression and PI3K/AKT activity. In contrast, silencing of $L H P P$ significantly promoted cell growth and proliferation by modulating the $P I 3 K / A K T$ signaling pathway. Notably, the anti-CRC effects of LHPP were also observed in nude mouse in vivo experiments. Overall, the data obtained in the present study suggested that $L H P P$ may be exploited as a diagnostic and prognostic candidate for patients with CRC.
\end{abstract}

\section{Introduction}

Colorectal cancer (CRC) is one of the most malignant tumors diagnosed in humans and $\mathrm{CRC}$ is the leading cause

Correspondence to: Dr Dongmin Chang, Department of Surgical Oncology, The First Affiliated Hospital of Xi'an Jiaotong University, 277 W Yanta Road, Xi'an, Shaanxi 710061, P.R. China

E-mail:dr_changdm@sina.com

*Contributed equally

Key words: colorectal cancer, LHPP, PI3K/AKT signaling pathway, proliferation of cancer-associated mortality worldwide. There were more than 145,600 patients diagnosed with CRC, and more than 50,000 individuals that succumbed to the disease in the United States in 2019 (1,2). The most common therapeutic interventions for patients with CRC include surgery, neo-adjuvant radiotherapy and adjuvant chemotherapy (for patients with stage III/IV and high-risk stage II colon cancer). Although the prognosis of patients with CRC has slowly improved in numerous countries due to the development of colonoscopy, the 5 -year relative survival has remained $<50 \%$ in low-income countries (3-5). Therefore, it is extremely urgent to elucidate the underlying molecular mechanisms and develop new therapeutic strategies.

LHPP is located on chromosome 10q26.13 and encodes a $29 \mathrm{kDa}$ enzyme called phospholysine phosphohistidine inorganic pyrophosphate phosphatase, which has been purified from bovine liver (6-10). The protein is able to hydrolyze imidodiphosphate, 3-phosphohistidine and 6-phospholysine. Currently, LHPP has been demonstrated as a tumor suppressor, which plays an essential role in inhibiting human hepatocellular carcinoma (HCC) progression by regulating $A K T$ expression level and activity (9). After analyzing The Cancer Genome Atlas (TCGA) and International Cancer Genome Consortium (ICGC) databases, researchers also demonstrated 49 LHPP mutations that are predicted to be inactivating mutations in other types of tumors, including esophageal cancer, head and neck cancer and stomach cancer. The biological effects of LHPP have also been identified in cervical cancer (11); the protein impedes cell growth, proliferation and metastasis, and promotes cell apoptosis.

The phosphatidylinositol-3-kinase/protein kinase B (PI3K/AKT) signaling pathway plays an extremely important role in diverse cellular functions, such as cell proliferation, differentiation, angiogenesis and autophagy $(8,12)$. Recently, a number of studies have demonstrated that the $P I 3 K / A K T$ signaling pathway is involved in the process of epithelial-mesenchymal transition (EMT) either directly or indirectly $(13,14)$. There are three groups of the PI3K family members, but only class IA PI3Ks play a role in tumorigenesis $(12,15)$. An increasing amount of evidence has demonstrated that the PIK3CA mutation exists in various types of tumor, including CRC. Of the patients with mutant 
CRC, 6-9\% possess a double mutation of PIK3CA (16-18). Thus, PI3K/AKT inhibitors (e.g., NVP-BEZ235, OSI-027 and BYL719) are used as promising drugs in the treatment of CRC (19).

The present study used western blotting and immunohistochemistry (IHC) to assess differences in LHPP expression between normal mucosa tissues and cancer tissues. The results revealed that LHPP expression was decreased in CRC tissues compared with that noted in the adjacent normal tissues. The clinical outcomes of patients with higher LHPP expression demonstrated improved survival. Thus, the present study predicted that LHPP could be a tumor suppressor in the progression of CRC. Subsequently, in the present study both in vitro and in vivo experiments were performed to investigate the role of $L H P P$ and its potential mechanisms. The results demonstrated that $L H P P$ could inhibit CRC cell growth and proliferation via the $P I 3 K / A K T$ signaling pathway. Therefore, LHPP could be considered as a promising target to develop novel therapeutic strategies against CRC.

\section{Materials and methods}

Bioinformatics prediction. The present study used gene data from The Cancer Genome Atlas (TCGA; https://cancergenome. nih.gov/) in order to evaluate the differences in LHPP mRNA expression between CRC tissues and matched noncancerous tissues. The median mRNA expression of $L H P P$ was regarded as the cut-off value to distinguish patients with high and low expression. The overall survival data were collected for further analysis. A total of 407 patients were selected in the present study (TCGA; https://cancergenome.nih.gov/).

Human samples. The present study obtained CRC tissues and their corresponding adjacent non-tumor tissues $(n=52)$ from patients (mean age 65 years; range, 54-78) at the First Affiliated Hospital of Xi'an Jiaotong University (Shaanxi, China) between June, 2016 and March, 2019. Each tissue was immediately frozen and stored in liquid nitrogen following surgery. All patients had not received chemotherapy or radiotherapy prior to the primary surgery. Overall survival was regarded as the primary point to evaluate the association between LHPP expression and clinical outcomes of patients with CRC. Other clinical parameters were selected for further analysis. Informed consent was obtained from each patient. The study protocol was approved by the Ethics Committee at the First Affiliated Hospital of Xi'an Jiaotong University (Shaanxi, China).

Immunohistochemistry (IHC). The human CRC, adjacent normal tissues and heterologous tumor tissues from nude mice were fixed in formaldehyde and embedded in paraffin. Prior to the immunostaining, 4- $\mu \mathrm{m}$-thick tissue sections were dewaxed in xylene and washed three times in PBS. The sections were then autoclaved in $10 \mathrm{mM}$ sodium citrate buffer $(\mathrm{pH}$ 6.0) for $10 \mathrm{~min}$ at $120^{\circ} \mathrm{C}$. The present study used goat serum $(10 \%)$ to block non-specific staining. The sections were incubated with rabbit polyclonal antibodies to LHPP (dilution 1:200, catalog no. 15759-1-AP; Proteintech) or Ki-67 (dilution 1:200, catalog no. 27309-1-AP; Proteintech) overnight at $4^{\circ} \mathrm{C}$. For the diagnosis, two independent investigators who were blinded to the study and the patient information performed the evaluations of the staining. The semi-quantitative immunoreactive score (IRS) of Remmele and Stegner was utilized to assess IHC scores $(20,21)$. The score was based on the percentage of positive cells ( 0 points, absence of cells with positive reaction; 1 point, $1-10 \%$ positive cells; 2 points, $11-50 \%$; 3 points, $51-80 \%$; 4 points, $>80 \%$ ) and the intensity of reaction color ( 0 , no reaction; 1 , low intensity; 2 , moderate intensity; 3 , intense color). The final score was the product of the two parameters ( $0-1$ point, negative; $2-3$ points, weakly positive; 4-5 points, positive; $>6$ points, strongly positive).

Cell lines and culture conditions. Human CRC cell lines (RKO, HT-29, SW480, CACO2 and HCT 116) were purchased from the Cell Bank of the Chinese Academy of Sciences (Shanghai). RKO, SW480 and CACO2 cells were cultured in complete RPMI-1640 medium (Hyclone; GE Healthcare). HT-29 and HCT116 cells were cultured in complete Dulbecco's modified Eagle's medium (DMEM; Hyclone; GE Healthcare). The medium was supplemented with $10 \%$ fetal bovine serum (FBS; Gibco; Thermo Fisher Scientific, Inc.) and a 1\% penicillin-streptomycin mixture. The cells were maintained at $37^{\circ} \mathrm{C}$ in a humidified incubator with $5 \% \mathrm{CO}_{2}$.

Immunofluorescence (IF) assay. In order to identify the location of LHPP in cells, SW480 and HT-29 cells (1x10 $)$ were seeded on slides in 24-well plates and cultured in an incubator containing $5 \% \mathrm{CO}_{2}$ at $37^{\circ} \mathrm{C}$ for $24 \mathrm{~h}$ with $500 \mu \mathrm{l}$ complete medium. Cells were fixed with $4 \%$ ice-cold paraformaldehyde for $20 \mathrm{~min}$, and $0.5 \%$ Triton X-100/PBS was used to permeabilize the cancer cells for $30 \mathrm{~min}$ at room temperature. The cells were then blocked with 10\% BSA for $1 \mathrm{~h}$ and incubated with a primary antibody against LHPP (dilution 1:30, catalog no. 15759-1-AP; Proteintech) overnight at $4^{\circ} \mathrm{C}$. Goat anti-rabbit IgG/RBITC (catalog no. BS-0295G, Bioss) was added for $\sim 1 \mathrm{~h}$ at room temperature. Cell nuclei were counter-stained with DAPI. Cells were observed under a fluorescence microscope (magnification, x200).

Cell transfection. A total $20-30 \%$ confluent SW480 cells were stably transfected with $L H P P$ lentiviruses (LV) or negative control lentiviruses according to the manufacturer's protocols (viral volume=MOI x cell numbers/viral titers; Shanghai GeneChem Co., Ltd.). We selected a multiplicity of infection (MOI) of 20 as the final parameter after pre-experiments. Lentiviral vectors overexpressing $L H P P$ were generated using a GV358 System (Shanghai China, GeneChem) and contained a U6 promoter-driven multiple cloning site (MCS) combined with a cytomegalovirus promoter-driven puromycin gene and green fluorescent protein. The GV248 RNA interference (RNAi) system (Shanghai China, GeneChem) contained a U6 promoter-driven multiple cloning site (MCS) combined with a cytomegalovirus promoter-driven puromycin gene and green fluorescent protein was used to generate lentiviruses expressing short hairpin RNA (shRNA) targeting LHPP. The target sequence of $L H P P$ was 5'-GAGCAAGGCCUGCGA CCAUTTAUGGUCGCAGGCCUUGCUCTT-3'. The negative lentiviruses (LV-NC-RNAi) were also purchased from Shanghai GeneChem. The negative sequence was 5'-UUCUCC GAACGUGUCACGUTT-3'. The HT-29 cell line was stably 
transfected with $L H P P-R N A i$ lentiviruses. After culturing for 2 days, the cells were purified with $3 \mu \mathrm{g} / \mathrm{ml}$ puromycin for $48 \mathrm{~h}$, and the concentration of puromycin was maintained with $1.5 \mu \mathrm{g} / \mathrm{ml}$ for 5 days. The overexpression and knockdown efficiency of $L H P P$ were assessed using western blotting, RT-PCR and fluorescence microscopy.

Western blot analysis. Total protein was extracted from cells or tissues using RIPA buffer with protease inhibitors. Protein concentrations were determined by using a BCA Protein assay kit (cat. no. PA115-01; Tiangen Biotech Co. Ltd.). Equal amounts of protein $(20-30 \mu \mathrm{g})$ were separated via SDS-PAGE $(10-12 \%$ gel) and then transferred to PVDF membranes. The membranes were blocked with $5 \%$ milk and incubated with primary antibodies overnight at $4{ }^{\circ} \mathrm{C}$, followed by incubation with the secondary antibody (dilution 1:5,000) for $2 \mathrm{~h}$ at room temperature. The antibodies used were as follows: LHPP (dilution 1:500, cat. no. 15759-1-AP; Proteintech), P53 (dilution 1:500, cat. no. 10442-1-AP; Proteintech), total AKT (dilution 1:1,000, cat. no. 10176-2-AP; Proteintech), p-AKT (phospho-Ser 473; dilution 1:500, cat. no. 11054; SAB), GAPDH (dilution 1:2,000, cat. no. 10494-1-AP; Proteintech), PCNA (dilution 1:2,000; cat. no. 10205-2-AP; Proteintech), CDK4 (dilution 1:2,000; cat. no. 49132; SAB), cyclin D1 (dilution 1:1,000; cat. no. WL01435a; Wanleibio), NME1 (dilution 1:1,000, cat. no. 11086-2-AP; Proteintech), PI3K (dilution 1:500, catalog no. 41339; SAB), p-PI3K (phospho-Tyr467, dilution 1:500, cat. no. 11508; SAB). The bands were visualized using Immobilion Western Chemilum HRP Substrate (cat. no. WBKLS0100; Millipore). The immunoreactive membranes were scanned using GE Amersham Imager 600 system (GE Healthcare). ImageJ software (National Institutes of Health) was used to examine gray values of each primary antibody and GAPDH. The ratio of gray value (primary antibody/GAPDH) was calculated using GraphPad Prism 6 software (GraphPad Software, Inc.). Each experiment was performed in triplicate.

$R N A$ extraction, reverse transcription $(R T)$ and $R T$-quantitative PCR (RT-qPCR). Total RNA was extracted from cells using a Fastagen 200 kit (Fastagen cat. no. 220010; Shanghai Fastagen Biotechnology Co., Ltd.) according to the manufacturer's protocol. cDNA was synthesized using PrimeScript $^{\mathrm{TM}}$ RT Master Mix (Takara Biotechnology). qPCR was performed using the SYBR Green PCR kit (Takara Biotechnology). Each experiment was performed in triplicate. The expression level of $L H P P$ was calculated using the $2^{-\triangle \triangle C q}$ method (22). The housekeeping gene GAPDH was applied as an internal control. The following primers were used: GAPDH forward, 5'-TCCCCATTGGACTTA CTTG-3' and reverse, 5'-AGTACAGTCGCGATAAGAG-3'; LHPP forward, 5'-GCTTCAGAGGCTGGGATTTGAC-3' and reverse, 5'-AATTACCACACAGTTTGGGTTGGA-3'. The thermal parameters were as follows: $95^{\circ} \mathrm{C}$ for $10 \mathrm{~min}$, followed by 40 cycles at $95^{\circ} \mathrm{C}$ for $15 \mathrm{sec}$ and $60^{\circ} \mathrm{C}$ for $1 \mathrm{~min}$.

Cell viability analysis. Cells were seeded at 2,000-3,000 cells per well in 96-well plates and subsequently cultured for 7 days. CCK- 8 solution $(10 \mu \mathrm{l})$ was added to each well and the cells were incubated for $2 \mathrm{~h}$ under aseptic conditions in a $5 \% \mathrm{CO}_{2}$ incubator at $37^{\circ} \mathrm{C}$. The spectrophotometric value of each sample was measured at $450 \mathrm{~nm}$.

Colony formation analysis. Cells were seeded at 1,000-2,000 cells per well, plated in 6-well plates, and incubated for 3-4 weeks at $37^{\circ} \mathrm{C}$ in a humidified environment with $5 \% \mathrm{CO}_{2}$. After three washes with PBS, the colonies were fixed with $4 \%$ paraformaldehyde, and then stained with crystal violet staining (1\%) solution for $30 \mathrm{~min}$ at room temperature. Then stained colonies were imaged using camera and counted using microscope.

Cell cycle analysis. Cells $\left(1-2 \times 10^{4}\right)$ were plated in 6-well plates and cultured for $24 \mathrm{~h}$. Cultured cells were digested and collected in $1.5 \mathrm{ml}$ EP tubes and fixed with $70 \%$ cold ethanol at $4^{\circ} \mathrm{C}$ overnight. Cells were then washed twice with cold PBS. Subsequently, the cells were incubated with $500 \mu \mathrm{l}$ propidium iodide (PI) and RNase A (1:9) for 30 min in darkness. A FACSCalibur flow cytometer (BD Bioscience) was used to analyze the results. Finally, the cell proportions at different phases of the cell cycle were calculated using Graphpad Prism 6 software (GraphPad Software, Inc.).

Xenograft assays. Four-week-old female specific pathogen-free (SPF) BALB/c nude mice (total number, 12) were purchased from Xian Jiaotong University Animal Laboratory for the subcutaneous xenograft experiments. LV-RNAi-LHPP and LV-SiNC HT-29 (HT-29 Sh-LHPP and HT-29 SiNC, respectively) cells $\left(2-4 \times 10^{6} / 200 \mu \mathrm{l}\right)$ were injected into mice subcutaneously (6 mice per group). Tumor size was measured using a caliper every 3 days and calculated using the following formula: Volume=length $\mathrm{x}\left(\mathrm{width}^{2}\right) / 2\left(\mathrm{~mm}^{3}\right)(23)$. Nude mice were humanely sacrificed after 3-4 weeks using cervical dislocation and tumors were isolated from the mice. Humane endpoints included i) tumor ulceration shows no stabilization within 7 days of treatment; ii) ulcerated tumor is actively bleeding; iii) ulcerated tumor shows visible signs of infection; iv) animals show discomfort associated with tumor ulceration such as biting/scratching; and v) tumor size did not exceed $20 \mathrm{~mm}(2.0 \mathrm{~cm})$ in mice (IACUC Guideline: Tumor Induction in mice and rats) (24-26). All the conditions of the animal laboratory conformed to the principles of Euroguide: On the accommodation and care of animals used for experimental and other scientific purposes (27). Tumor tissues were fixed in $4 \%$ paraformaldehyde and cut into $10-\mu \mathrm{m}$ sections for IHC analysis.

Statistical analysis. All statistical data were analyzed using GraphPad Prism 6 software (GraphPad Software, Inc.). Experiments were performed in triplicate and data are expressed as the mean \pm standard error. The two-tailed Student's $t$ test was used to analyze the statistical significance in continuous variables between two different groups. One-way or two-way analysis of variance (ANOVA) followed by Bonferroni's Multiple Comparison Test was performed to test differences between multiple groups. Next, the $\chi^{2}$ test was used to evaluate the association between LHPP expression and clinical characteristics of the patients with CRC. Survival curves were created using the Kaplan-Meier method, and the positive difference between groups was analyzed using the 
Table I. Correlation between LHPP expression and clinicopathological characteristics of the patients with colorectal cancer $(n=52)$.

\begin{tabular}{|c|c|c|c|c|c|}
\hline \multirow[b]{2}{*}{ Characteristics } & \multicolumn{2}{|c|}{$\begin{array}{l}\text { LHPP gene expression } \\
\text { (no. of patients) }\end{array}$} & \multirow[b]{2}{*}{ Total } & \multirow[b]{2}{*}{$\chi^{2}$} & \multirow[b]{2}{*}{ P-value } \\
\hline & Low & High & & & \\
\hline Age (years) & & & & 2.507 & 0.113 \\
\hline$\leq 60$ & 12 & 12 & 24 & & \\
\hline$>60$ & 20 & 8 & 28 & & \\
\hline Sex & & & & 0.430 & 0.624 \\
\hline Male & 18 & 9 & 27 & & \\
\hline Female & 14 & 11 & 25 & & \\
\hline T classification & & & & 5.967 & 0.015 \\
\hline $\mathrm{T} 1+\mathrm{T} 2$ & 7 & 11 & 16 & & \\
\hline $\mathrm{T} 3+\mathrm{T} 4$ & 25 & 9 & 36 & & \\
\hline $\mathrm{N}$ classification & & & & 5.609 & 0.018 \\
\hline No & 15 & 16 & 31 & & \\
\hline $\mathrm{N} 1+\mathrm{N} 2$ & 17 & 4 & 20 & & \\
\hline M classification & & & & 0.797 & 0.372 \\
\hline M0 & 28 & 19 & 47 & & \\
\hline M1 & 4 & 1 & 5 & & \\
\hline Stage classification & & & & 5.852 & 0.016 \\
\hline Stage I+II & 13 & 15 & 28 & & \\
\hline Stage III+IV & 19 & 5 & 24 & & \\
\hline Longest tumor dimension $(\mathrm{cm})$ & & & & 6.857 & 0.009 \\
\hline$\leq 1.5$ & 9 & 13 & 22 & & \\
\hline$>1.5$ & 23 & 7 & 30 & & \\
\hline Survival status & & & & 1.328 & 0.249 \\
\hline Living & 13 & 5 & 18 & & \\
\hline Deceased & 19 & 15 & 34 & & \\
\hline
\end{tabular}

LHPP, phospholysine phosphohistidine inorganic pyrophosphate phosphatase. Bold print indicates a significant correlation between LHPP expression and clinicopathological characteristics.

log-rank test. $\mathrm{P}<0.05$ was consisted to indicate a statistically significant difference.

\section{Results}

Expression of LHPP is lower in CRC tissues compared with that in the matched normal tissues. LHPP is dysregulated in patients with CRC. The present study used data published in TCGA to examine the expression of $L H P P$ in CRC. The results published or shown here are in whole or part based upon data generated by the TCGA Research Network: https://www.cancer.gov/tcga. LHPP expression was markedly lower in CRC tissues compared with that noted in the normal tissues (normal, 51; cancer, 384; $\mathrm{P}<0.0001$; Fig. 1A). The $L H P P$ expression was also significantly decreased in cancer tissues when compared with the matched noncancerous tissues (normal, 28; cancer, 28; $\mathrm{P}<0.0001$; Fig. 1B). However, no significant difference in the overall survival was observed between patients with high and low expression of LHPP (median expression, 8.3611; $\mathrm{n}=182 ; \mathrm{P}=0.4357$; Fig. 1C).
The present study then used IHC to identify the LHPP expression in cancer samples. The results of the IHC staining are presented in Fig. 2A; CRC tissues exhibited a lower positive rate of LHPP staining compared with adjacent normal tissues. GraphPad Prism 6 software was used to calculate IHC scores (Fig. 2B). The data suggested that cancer tissues had markedly lower IHC scores when compared with the adjacent normal tissues $(n=52 ; \mathrm{P}<0.0001)$. Moreover, the protein levels of LHPP in CRC samples were significantly lower than these levels in the matched noncancerous samples (Fig. $2 \mathrm{C}$ and D). After further analysis, the data from the present study revealed that patients with higher expression levels of LHPP were in the early stages of disease (Stage I+II; $\mathrm{P}<0.05$ ). In addition, lower expression levels of LHPP were positively associated with advanced $\mathrm{T}$ classifications $(\mathrm{P}<0.05)$, lymph node metastasis $(\mathrm{P}<0.05)$ and long dimension of CRC $(\mathrm{P}<0.01)$ (Table I). There were no significant differences observed between LHPP expression level and other pathological data. The present study then selected an IHC score of 3 points as the cut-off value to distinguish 

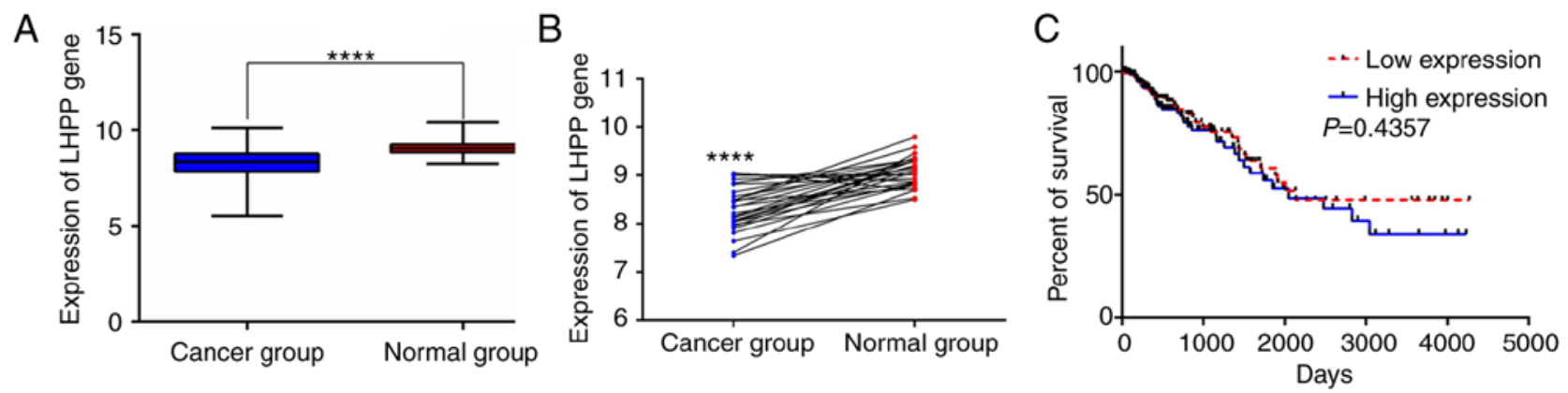

Figure 1. (A and B) Decreased expression of $L H P P$ in colorectal cancer tissues when compared with normal tissues from the TCGA database. (C) No significant difference in overall survival was observed between patients from the TCGA database with high $L H P P$ expression. ${ }^{* * * *} \mathrm{P}<0.0001$. $L H P P$, phospholysine phosphohistidine inorganic pyrophosphate phosphatase; TCGA, The Cancer Genome Atlas.
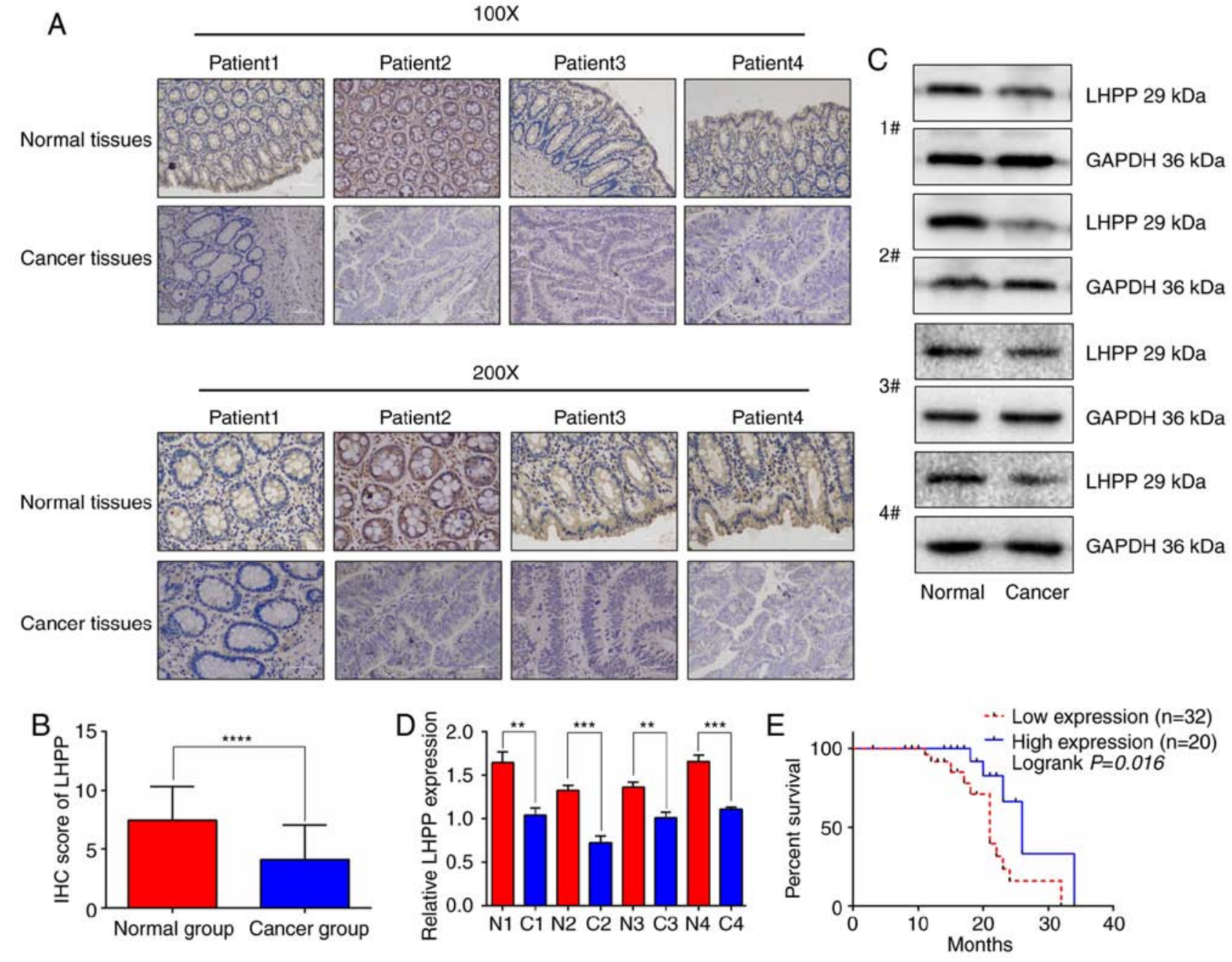

Figure 2. (A) Protein expression of LHPP was detected via IHC. (B) Significant differences were observed between normal tissues and cancer tissues by calculating the IHC scores. (C) The protein expression of LHPP was downregulated in cancer tissues of four patients with CRC. (D) Relative protein expression levels of LHPP were calculated using GraphPad Prism 6 software. N1-N4, normal tissues; C1-C4, cancer tissues. (E) Patients recruited from the First Affiliated Hospital of Xi'an Jiaotong University with high expression levels of LHPP had an improved overall survival rate. ${ }^{* *} \mathrm{P}<0.01,{ }^{* * * *} \mathrm{P}<0.001,{ }^{* * * * *} \mathrm{P}<0.0001$. IHC, immunohistochemistry; LHPP, phospholysine phosphohistidine inorganic pyrophosphate phosphatase; CRC, colorectal cancer.

patients in the two groups. Notably, the results demonstrated that patients with higher expression levels of LHPP exhibited extended overall survival (Fig. 2E). The median survival of patients in the higher expression group was 26.0 months, which was significantly better than patients in the lower expression group (median survival, 21.0 months; $\mathrm{P}<0.05$ ).
Cell transfection results. The present study analyzed the expression levels of LHPP in different CRC cell lines (RKO, HT29, SW480, CACO2 and HCT116) via western blotting (Fig. 3A and B). The data suggested that HT-29 and HCT116 had higher expression levels of LHPP. Lower expression levels of LHPP were observed in CACO2 and RKO cell lines. The SW480 
A

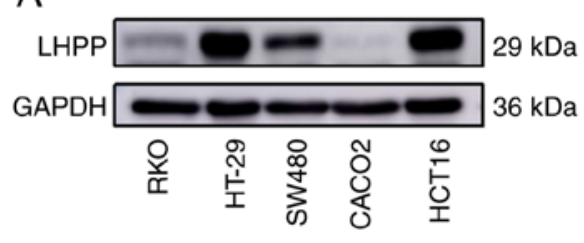

$\mathrm{B}$
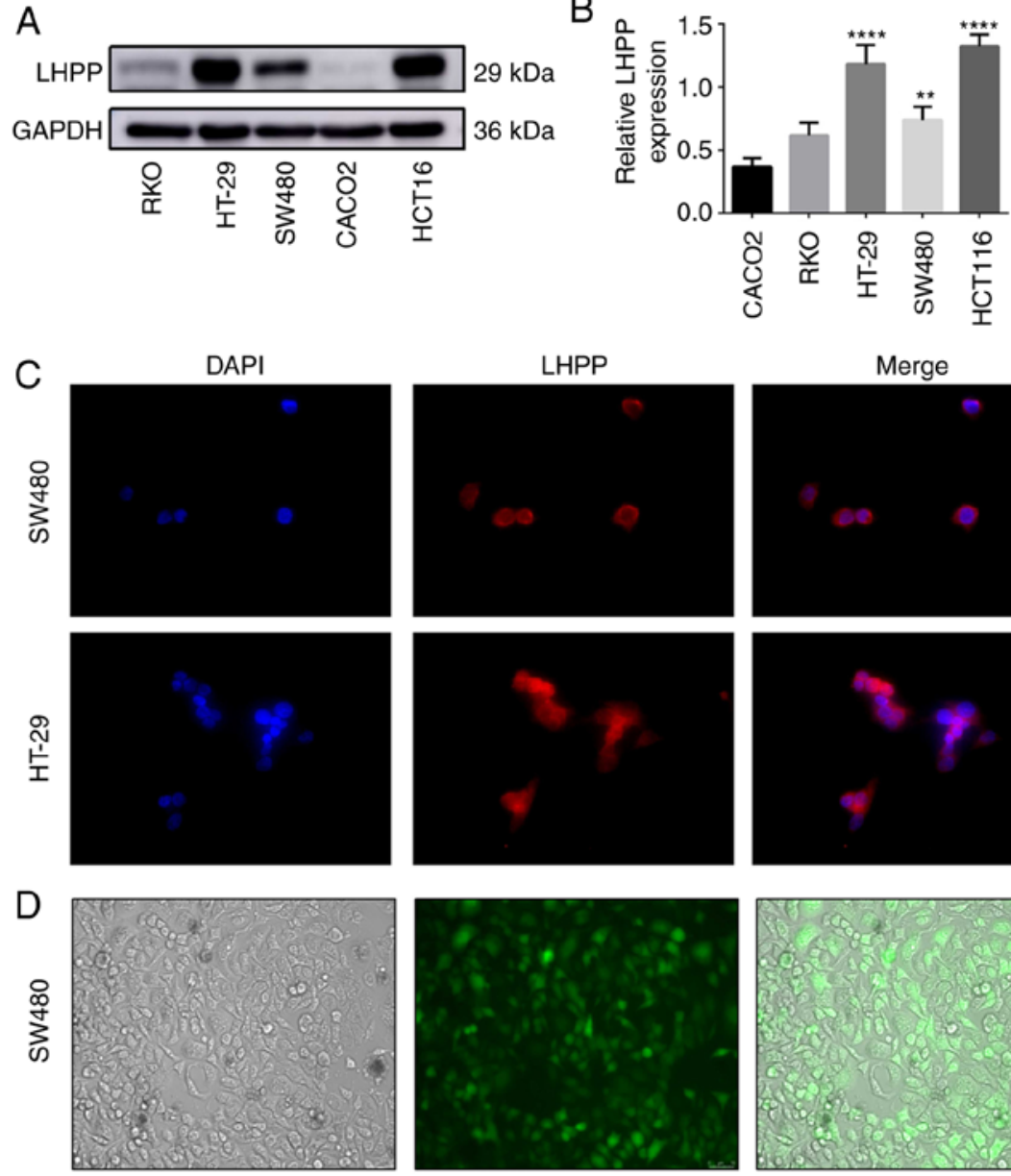
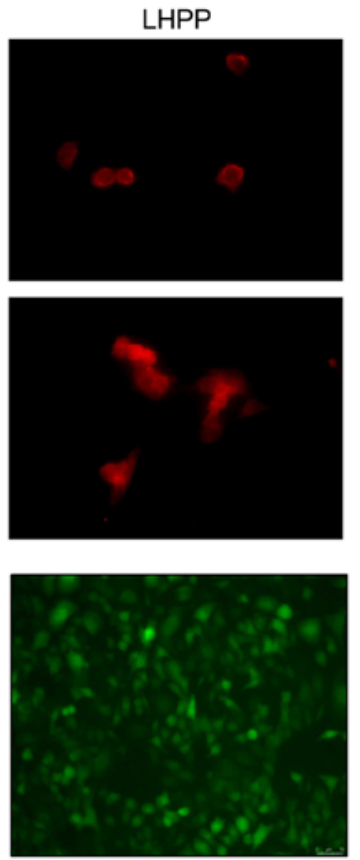
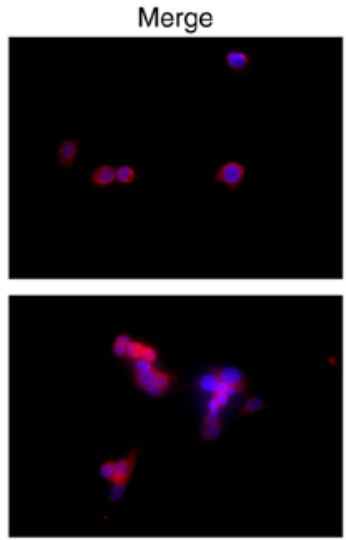
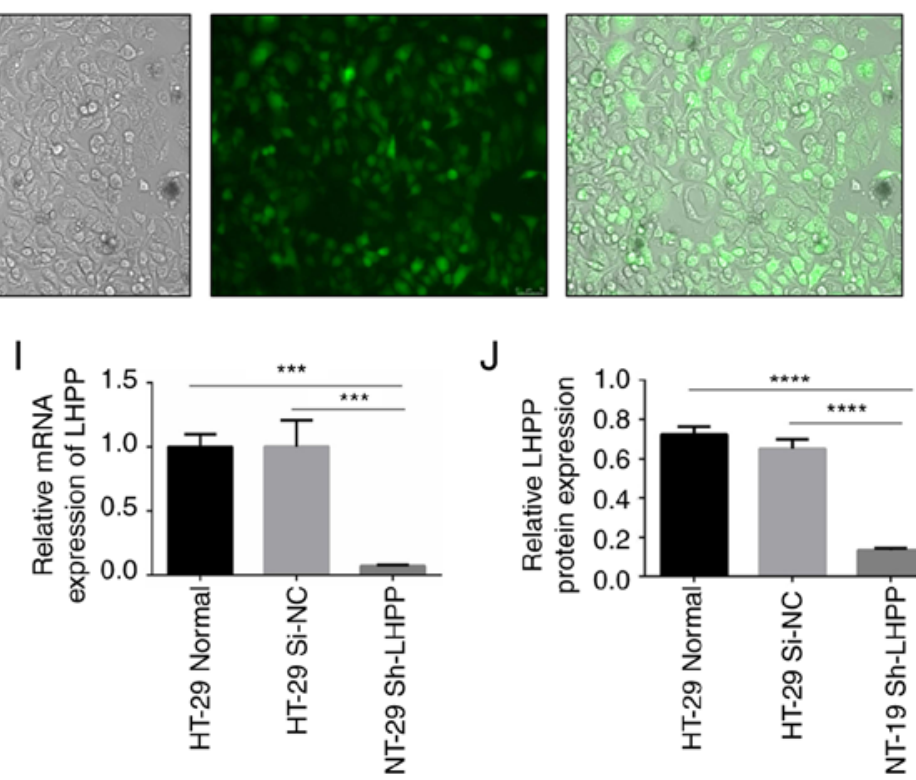

$\mathrm{J}$

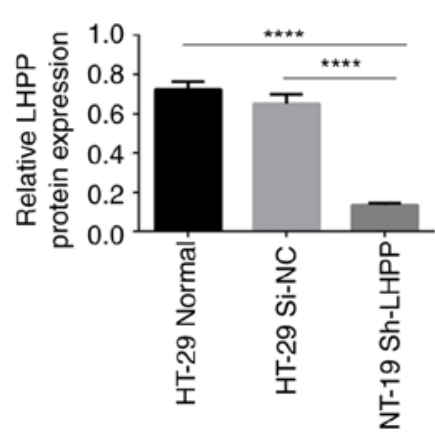

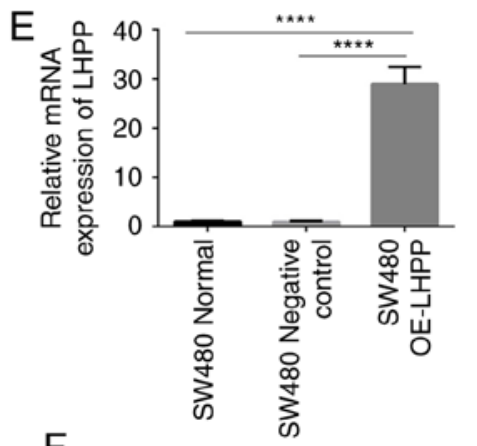

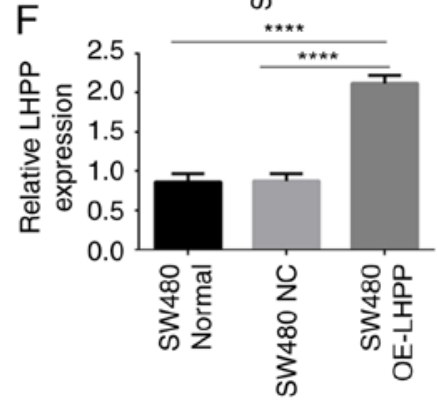

G

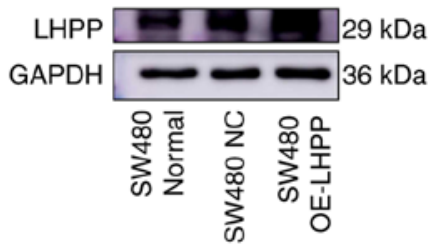

$\mathrm{H}$

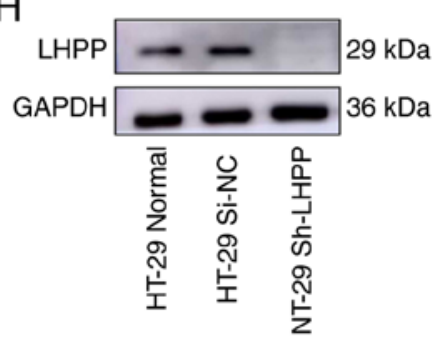

Figure 3. (A) Expression levels of LHPP in different CRC cell lines. (B) Relative protein expression levels of LHPP were calculated using GraphPad Prism 6 software, All protein expression levels were compared with LHPP expression of the CACO2 cell line which was exhibited the lowest protein expression. (C) LHPP protein was localized in the cell cytoplasm. (D) SW480 cells expressed green fluorescent protein; these results indicated that the transfection efficiency was $>80 \%$. (E-G) Confirmation of LHPP overexpression in the SW480 cell line (SW480 OE-LHPP group) following transfection with lentiviruses using RT-qPCR and western blotting. (H-J) Effect of LHPP-knockdown lentiviruses on LHPP expression in the HT-29 cell line (HT-29 Sh-LHPP group) compared to the negative control group (HT-29 Si-NC). ${ }^{* *} \mathrm{P}<0.01,{ }^{* * *} \mathrm{P}<0.001,{ }^{* * * *} \mathrm{P}<0.0001$. LHPP, phospholysine phosphohistidine inorganic pyrophosphate phosphatase; CRC, colorectal cancer.

cell line presented with a median expression level of LHPP among the cell lines. Thus, the present study selected SW480 and HT-29 cell lines for the subsequent analyses. It was revealed that the LHPP protein was located in the cytoplasm in SW480 and HT-29 cells when using immunofluorescence (Fig. 3C).

In order to investigate the biological functions of $L H P P$, SW480 cells were stably transfected with LHPP lentiviruses according to the manufacturer's protocol (GeneChem). As illustrated in Fig. 3D, SW480 cells expressed green fluorescent protein; these results suggested that the transfection efficiency was $>80 \%$. As presented in Fig. 3E-G, the relative mRNA and protein expression levels of $\angle H P P$ were markedly higher in the SW480 OE- LHPP groups when compared with the negative control (SW480 NC) groups $(\mathrm{P}<0.0001)$.

In order to further investigate the role of LHPP in CRC, HT-29 cells were transfected with LHPP shRNA lentiviruses or negative control lentiviruses. The results are presented in Fig. 3. HT-29 cells in the shRNA-LHPP (HT-29 Sh-LHPP) 

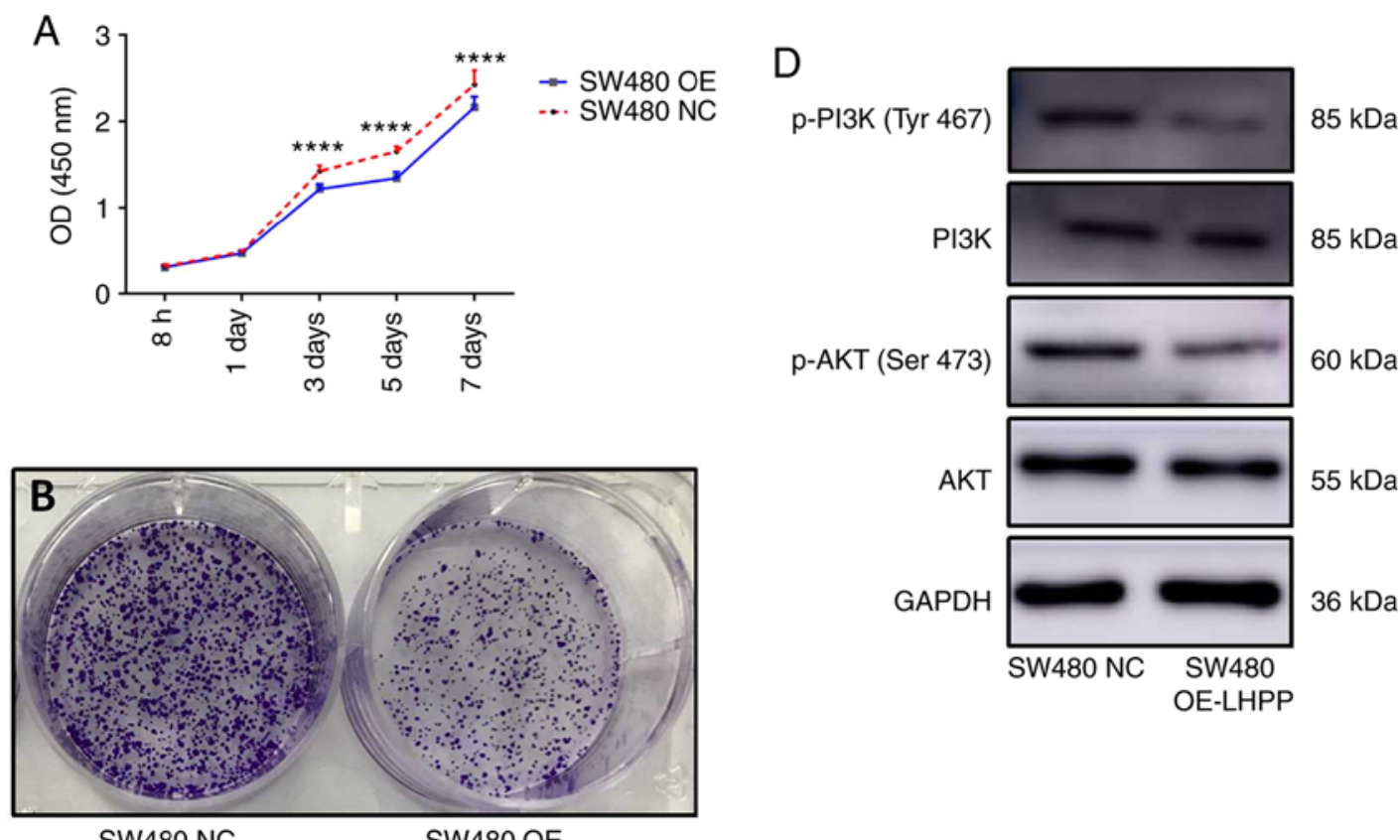

SW480 NC

SW480 OE
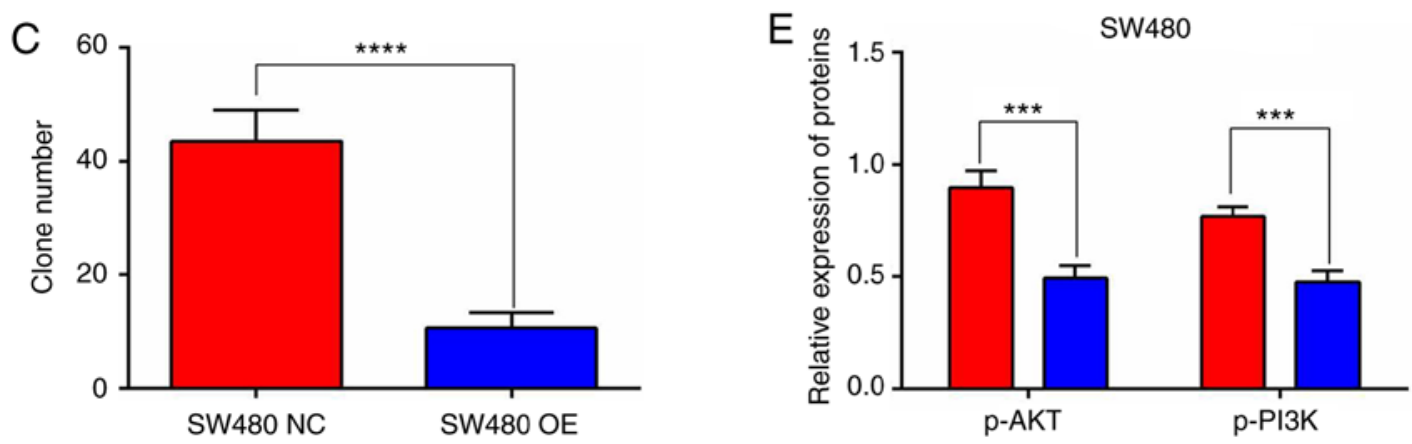

Figure 4. (A-C) Effects of LHPP upregulation on the growth and proliferation of the SW480 cell line, as determined by the CCK-8 and colony formation assays . (D and E) The expression levels of AKT, PI3K, phosphorylated (p)-AKT and p-PI3K in the LHPP overexpression (SW480 OE-LHPP) group were higher than these levels in the negative control (SW480 NC) group. ${ }^{* * *} \mathrm{P}<0.001,{ }^{* * * * *} \mathrm{P}<0.0001$. LHPP, phospholysine phosphohistidine inorganic pyrophosphate phosphatase; P13K, phosphatidylinositol-3-kinase; AKT, protein kinase B.

groups exhibited significantly lower LHPP mRNA $(\mathrm{P}<0.001)$ and protein expression $(\mathrm{P}<0.0001)$ levels when compared with the negative control groups (HT-29 Si-NC) (Fig. 3H-J).

Overexpression of LHPP suppresses CRC cell growth and proliferation, and decreases $p-P I 3 K / p$-AKt expression levels. The CCK- 8 assay and colony formation assay were used to investigate cell viability in the present study. The viability of SW480 cells was decreased in the SW480 OE-LHPP group after transfection for 3,5 and 7 days (Fig. 4A). The colony formation assay also demonstrated that overexpression of $L H P P$ could significantly suppress CRC cell proliferation (Fig. 4B and C; SW480 OE-LHPP group vs. NC group; $\mathrm{P}<0.0001)$. It is already well established that the PI3K/AKT axis plays a pivotal role in the development of cancer; therefore, the expression levels of AKT, PI3K, p-AKT $\left(\mathrm{Ser}^{473}\right)$ and p-PI3K $\left(\mathrm{Tyr}^{467}\right)$ were detected via western blotting in the present study. The expression levels of p-AKT and p-PI3K were significantly decreased in the SW480 OE-LHPP groups compared with the SW480 NC groups (Fig. 4D and E; P<0.001). These results suggest that upregulation of $L H P P$ may inhibit the activity of the PI3K/AKT signaling pathway.
Knockdown of LHPP promotes CRC growth and proliferation through the PI3K/AKT pathway. Both the CCK-8 and colony formation assays indicated that knockdown of $L H P P$ promoted cell growth and proliferation (Fig. 5A-C), which was consistent with the results in the $L H P P$ overexpression groups. Subsequently, AKT, PI3K, p-AKT and p-PI3K proteins were also examined via western blotting. It was revealed that HT-29 cells in the HT-29 Sh-LHPP groups had significantly higher expression levels of p-AKT and p-PI3K than these levels noted in the negative control (HT-29 Si-NC) groups (Fig. 5D and E; $\mathrm{P}<0.01$ and $\mathrm{P}<0.001$, respectively).

LHPP influences tumor growth in vivo. In order to confirm whether LHPP expression could impact the progression of CRC in vivo, HT-29 cells stably transfected with shRNA-LV (HT-29 Sh-LHPP) and negative control lentiviruses (HT-29 $\mathrm{Si}-\mathrm{NC})$ were injected into nude mice; each group contained six mice. As presented in Fig. 6A-D, tumors in the HT-29 Sh-LHPP group grew significantly larger and heavier than tumors in the si-NC group $(\mathrm{P}<0.01)$. The expression of LHPP was confirmed via IHC (Fig. 6G), and tumor tissues were confirmed by H\&E (Fig. 6E). Ki-67 is a biomarker of cell 

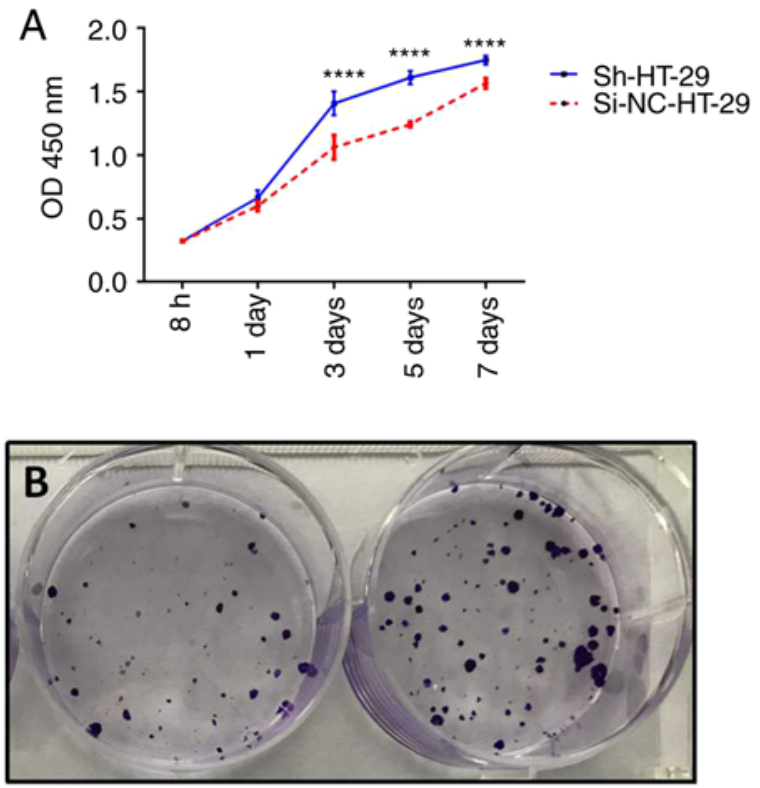

HT-29 Si-NC

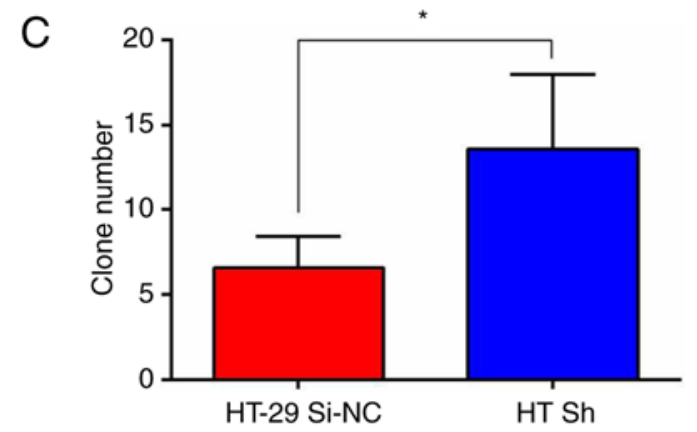

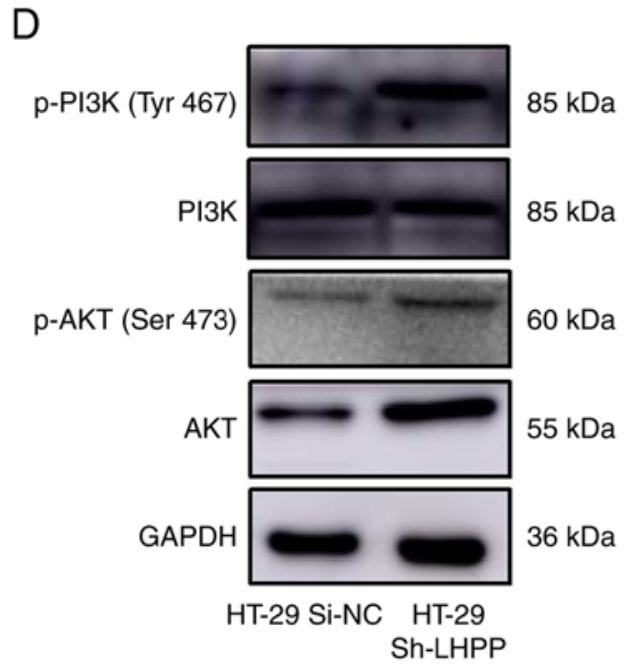

$\mathrm{E}$

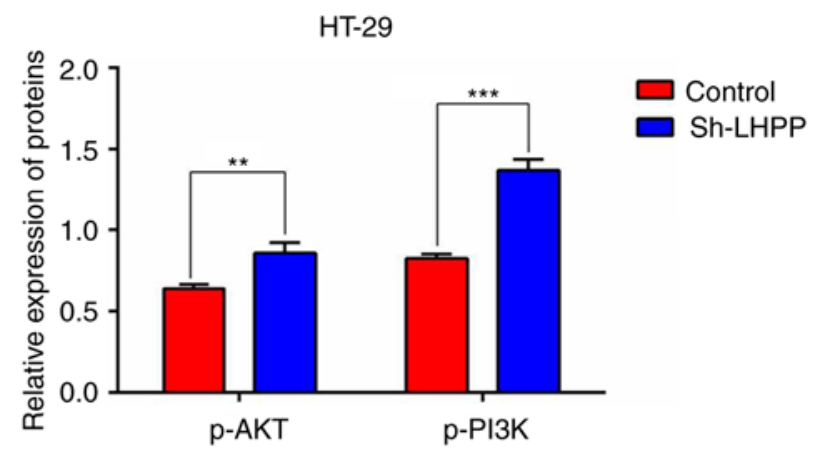

Figure 5. (A-C) Knockdown of LHPP expression in HT-29 cells promoted the growth and proliferation of the HT-29 Sh-LHPP cell line as compared with the negative control group (HT-29 Si-NC), as determined by CCK-8 and colony formation assays. (D and E) The expression levels of AKT, PI3K, p-AKT and p-PI3K in the LHPP knockdown group (HT-29 Sh-LHPP) and negative control (HT-29 Si-NC) groups. ${ }^{*} \mathrm{P}<0.05,{ }^{* * *} \mathrm{P}<0.01,{ }^{* * * *} \mathrm{P}<0.001,{ }^{* * * * *} \mathrm{P}<0.0001$. LHPP, phospholysine phosphohistidine inorganic pyrophosphate phosphatase; P13K, phosphatidylinositol-3-kinase; AKT, protein kinase B.

proliferation in the diagnosis of CRC. Therefore, the proportions of Ki-67-positive cells were assessed using IHC. The results revealed that positive $\mathrm{Ki}-67$ staining was much stronger in the HT-29 Sh-LHPP group (Fig. 6F). These in vivo data demonstrated that $L H P P$ may act as a tumor suppressor to decrease cancer growth.

Cell cycle is influenced by LHPP expression. CCK-8 assay and colony formation indicated that $L H P P$ overexpression could inhibit cell proliferation and tumor growth. In order to reveal the molecular mechanisms underlying the suppressive effect of LHPP on cell proliferation and tumor growth, the present study used flow cytometry to analyze the cell cycle after PI staining. Notably, the flow cytometry results revealed that $L H P P$ overexpression contributed to an increase in the $\mathrm{G}_{0} / \mathrm{G}_{1}$-phase and a decrease in S-phase of SW480 cells (Fig. 7A and B). In addition, the percentage of cells in the $\mathrm{G}_{2}$ phase was elevated in the $O E-L H P P$ group. On the contrary, the knockdown of $L H P P$ caused a marked decrease in the cell proportions of $\mathrm{G}_{0} / \mathrm{G}_{1}$-phase and a significant increase in S-phase (Fig. 7C and D). These data were consistent with previous experiments.
It has been well established that cyclin D1/CDK4 and P53 are crucial regulators of $\mathrm{G}_{1}-\mathrm{S}$ transition. The present study assessed expression changes of cyclinD1/CDK4 and P53 following LHPP upregulation and downregulation. As presented in Fig. 7E and F, LHPP markedly promoted the expression of P53 $(\mathrm{P}<0.05)$ and suppressed the expression of cyclinD1/CDK4 $(\mathrm{P}<0.01)$, while depletion of LHPP significantly upregulated cyclinD1/CDK4 expression $(\mathrm{P}<0.01)$ and inhibited P53 expression ( $\mathrm{P}<0.001)$ (Fig. 7E and $\mathrm{G})$. These data demonstrated that cell cycle arrest in the $\mathrm{G}_{0} / \mathrm{G}_{1}$ phase mediated by LHPP may be associated with the expression levels of P53 and cyclinD1/CDK4.

\section{Discussion}

Phospholysine phosphohistidine inorganic pyrophosphate phosphatase (LHPP) is a novel protein histidine phosphatase that is associated with protein homodimerization and inorganic diphosphatase activity $(6,10)$. It hydrolyzes P-N bonds in synthetic substrates in vitro with low efficiency. LHPP is conserved from the worm to the human and is poorly characterized $(28,29)$. Recently, low expression of LHPP was observed 

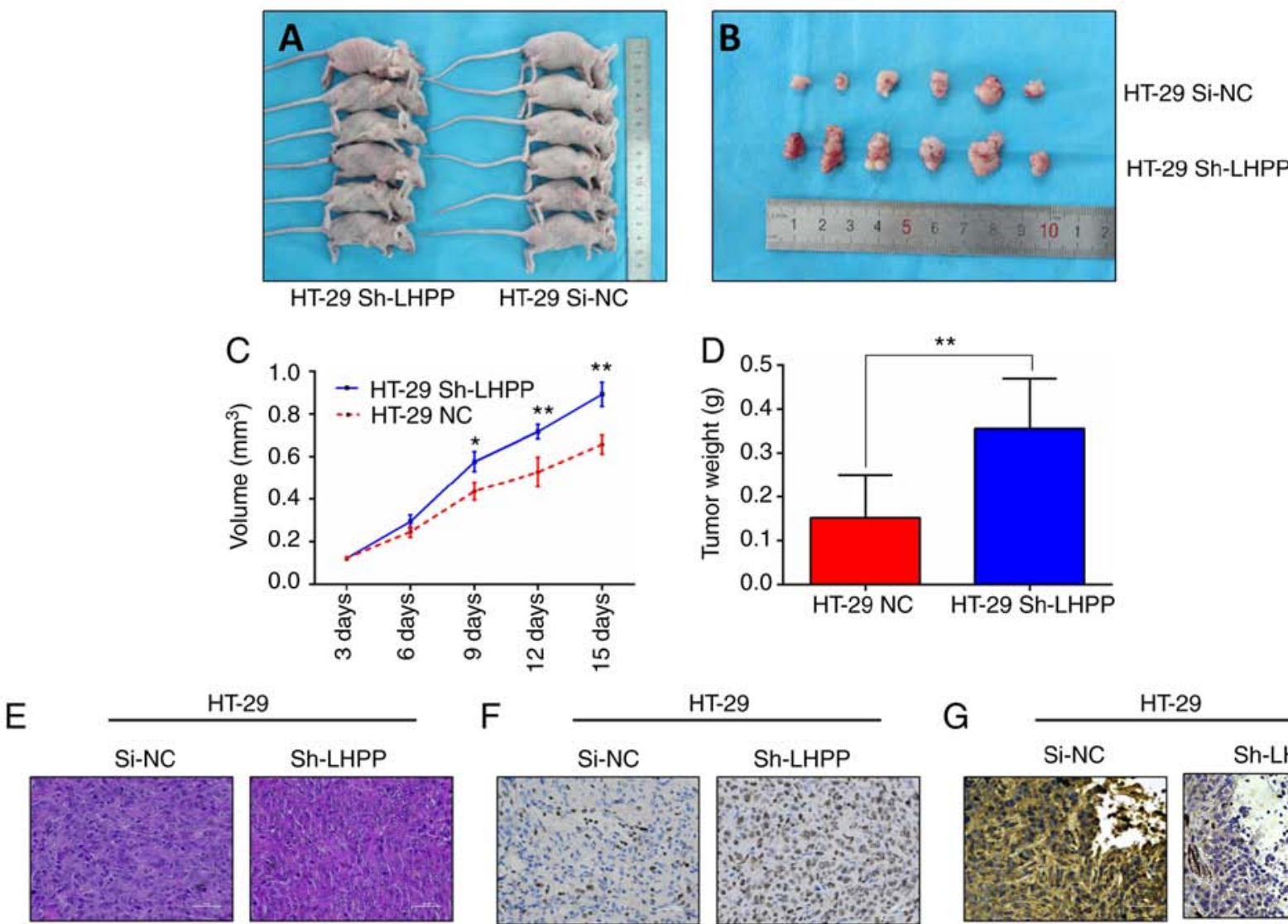

HT-29

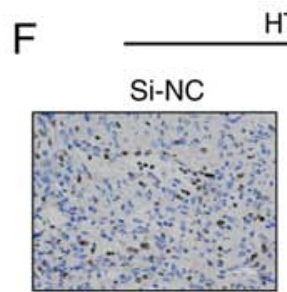

HT-29
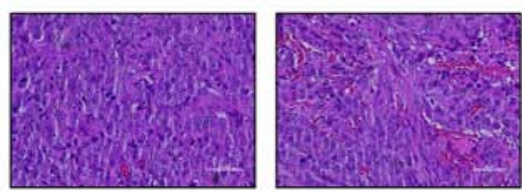

H\&E (200X)

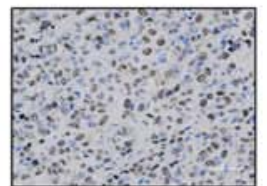

Ki-67 (200X)

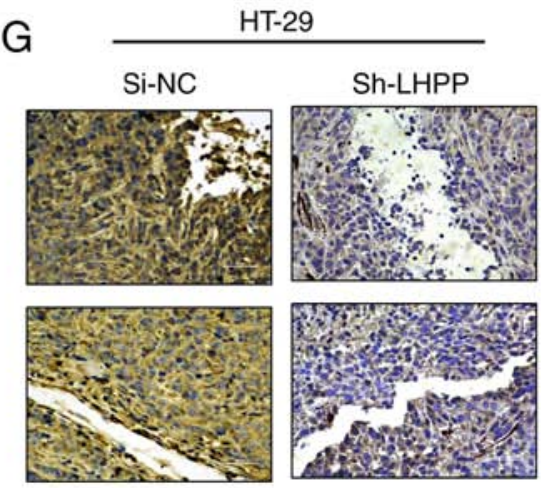

$\operatorname{LHPP}(200 \mathrm{X})$

Figure 6. (A and B) Images of xenograft tumors in the mice inoculated with the LV-RNAi LHPP knockout HT-29 cells (HT-29 Sh-LHPP) and negative control $(\mathrm{si}-\mathrm{NC})(\mathrm{n}=12)$ cells. (C and D) The tumor weight and volume ( $\mathrm{g}$ in weight and $\mathrm{mm}^{3}$ in volume) in the HT-29 Sh-LHPP group and si-NC group were quantitatively analyzed using GraphPad Prism 6 software. (E) Images of mouse tumor sections stained with hematoxylin and eosin (H\&E). (F) Cell proliferation in tumors isolated from the HT-29 Sh-LHPP or HT-29 si-NC groups were determined by Ki-67 staining. (G) The expression of LHPP was confirmed via IHC. ${ }^{*} \mathrm{P}<0.05,{ }^{* * *} \mathrm{P}<0.01$. LHPP, phospholysine phosphohistidine inorganic pyrophosphate phosphatase.

in a hepatocellular carcinoma (HCC) mouse model generated by deletion of PTEN and TSC1 (9). Moreover, a decrease in LHPP was associated with tumor severity and worse overall survival in patients with HCC. Consistently, these results were also identified in cervical cancer. Zheng et al (11) suggested that upregulation of LHPP could inhibit cell proliferation, metastasis and promote apoptosis in cervical cancer cells by modulating AKT level. Furthermore, patients with low expression levels of LHPP exhibited markedly larger tumor size, advanced FIGO stage and lymph node metastasis. Thus, LHPP may act as a tumor suppressor to inhibit the development of tumors.

The present study focused on the role of LHPP in colorectal cancer (CRC) proliferation. It was revealed that LHPP expression was clearly lower in patients with CRC compared with matched adjacent normal tissues. Patients with lower LHPP expression levels exhibited significantly larger tumor size, advanced-stage disease and lymph node metastasis. Furthermore, LHPP expression was also associated with clinical outcomes. Patients in the high LHPP expression group had a prolonged overall survival compared with patients in the low group (median survival time, 26.0 months vs. 21.0 months; $\mathrm{P}<0.01)$. These results were not consistent with data from the The Cancer Genome Atlas (TCGA) database. Three reasons may be attributed to the difference between the two clinical research findings. First, the limited sample size may have had a crucial impact on the clinical research in the present study $(\mathrm{n}=52)$; second, genetic mutations in the Chinese Han population were slightly different from mutations found in foreign population. Third, surgical skill may play a crucial role in the final outcome of patients with CRC. Therefore, future studies should utilize an increased number of patient cases. In order to investigate the functions of $L H P P$ in the development of CRC, cell lines (SW480 and HT-29) were stably transfected with $O E-L H P P$ and ShRNA-LHPP lentiviruses. The data revealed that overexpression of LHPP suppressed CRC cell growth and proliferation both in vitro and in vivo. The cell cycle was arrested in the $G_{0} / G_{1}$ phase after increasing the expression of LHPP, whereas knockdown of LHPP exhibited the opposite effects. 

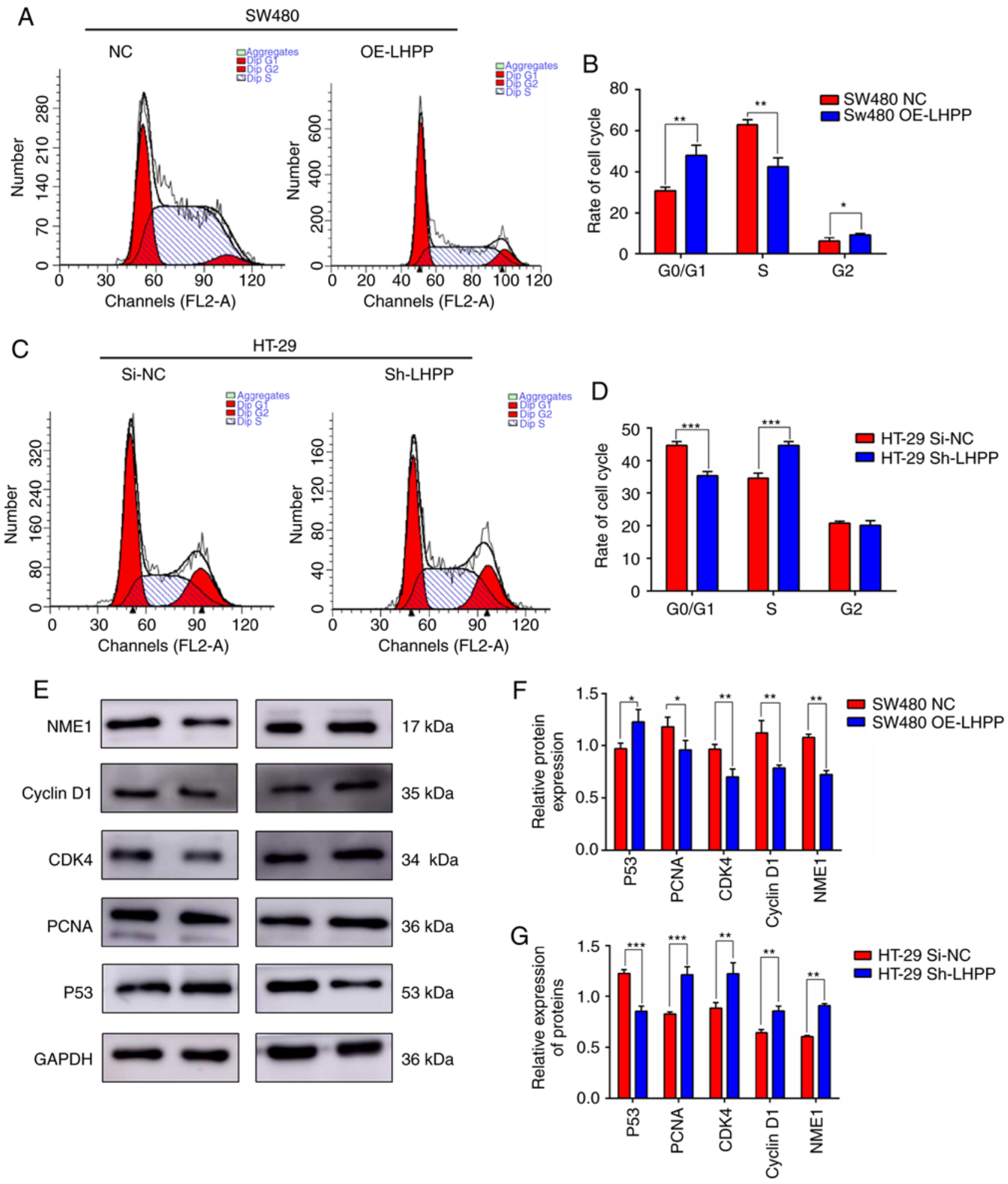

Figure 7. (A) Effect of LHPP overexpression on cell cycle distribution; representative images of DNA content determined by PI staining and flow cytometric analysis. (B) The percentages of cells in the $\mathrm{G}_{0} / \mathrm{G}_{1}, \mathrm{~S}$ and $\mathrm{M}$ phases in the LHPP overexpression SW480 cell line (SW480 OE-LHPP) compared with the negative control (SW480 Si-NC). (C) The effect of LHPP downregulation on cell cycle distribution; representative images of DNA content determined by PI staining and flow cytometry analysis. (D) The percentage of cells at the $\mathrm{G}_{0} / \mathrm{G}_{1}, \mathrm{~S}$ and $\mathrm{M}$ phases in the LHPP-depleted HT-29 cell line (HT-29 Sh-LHPP) compared with the negative control (HT-29 Si-NC). (E) Expression of proteins (NME1-1, cyclin D1, CDK4, PCNA and P53) was examined via western blotting. (F) Relative expression of proteins was calculated using GraphPad Prism 6 in the OE-LHPP groups. (G) Relative expression of proteins was calculated using GraphPad Prism 6 in the Sh-LHPP groups. " $\mathrm{P}<0.05,{ }^{* * *} \mathrm{P}<0.01,{ }^{* * *} \mathrm{P}<0.001$. LHPP, phospholysine phosphohistidine inorganic pyrophosphate phosphatase; PCNA, proliferating cell nuclear antigen (PCNA); CDK4, cyclin-dependent kinase 4; NME1-1, nucleoside diphosphate kinase A 1.

Cyclin D1 and CDK4 (cyclin-dependent kinase 4) have been confirmed as pivotal regulators in the cell cycle. CDK4/cyclin D1 complex phosphorylates and inactivates the retinoblastoma $(\mathrm{Rb})$ protein family (p107, $\mathrm{pRb}$ and p130) (30,31). Phosphorylation of Rb proteins contributes to the activation and upregulation of E2F target genes, such 
as E-type cyclins, which promotes cell proliferation through from the $G_{1}$ phase to $S$ phase (32). To date, evidence have demonstrated that upregulation of the cyclinD1/CDK4 axis is extremely important in tumor growth. The present study also confirmed that an increased LHPP level inhibited the expression of cyclinD1/CDK4 in CRC cells. On the contrary, upregulation of cyclinD1 and CDK4 was observed following LHPP knockdown. These results suggest that LHPP may influence activation of the cyclinD1/CDK4 axis to inhibit tumor proliferation. Proliferating cell nuclear antigen (PCNA) (33) is a bio-marker of proliferation in the diagnosis of tumors. Its expression is significantly increased during the $\mathrm{S}$ phase of the cell cycle (34). PCNA promotes DNA synthesis of the leading strand and replication of the lagging strand (35). In the present study, the expression level of PCNA was decreased by LHPP activation. Thus, CRC cells were arrested in the $\mathrm{G}_{0} / \mathrm{G}_{1}$ phase. These findings indicate that LHPP impedes cancer cell growth and proliferation by modulating various target proteins.

Tumor suppressor p53 is a key negative regulator of the cell cycle, as well as cell apoptosis, invasion and migration (36). Under normal conditions, the expression level of p53 is low. However, as a transcription factor, activated p53 could bind to a number of target genes and lead to various functions, such as cell cycle arrest and apoptosis, in response to stress signals $(36,37)$. For instance, p53 promotes the activation of mitochondrial and death receptor-induced apoptotic pathways to mediate cell apoptosis. Cell cycle arrest induced by p53 requires $\mathrm{p} 21$, which is the downstream gene of $\mathrm{p} 53$ and a type of cyclin-dependent kinase inhibitor (38). Thus, p53 acts as a critical barrier against tumor growth. Consistently, the results from the present study indicated that cell cycle arrest in the $\mathrm{G}_{0} / \mathrm{G}_{1}$ phase was also associated with p53 expression. Knockdown of LHPP markedly decreased p53 expression level, contributing to the progression of CRC cells.

Histidine phosphorylation is a common but poorly characterized method of post-translational modification of proteins (39). NME1 and NME2 are homologous proteins (88\% identical) that, to the best of our knowledge, are currently the only known mammalian histidine kinases (40). Hindupur et al indicated that NME1/NME2 activation, in a background of low LHPP expression, is a crucial event in the development of liver cancer (9). Proteomic analyses of tumors from HCC mouse models revealed that the expression levels of nucleoside diphosphate kinase A and B (NME1 and NME2) were upregulated when compared with the control group. The data also revealed that the expression level of NME1 was opposite to that of LHPP activity (9). Thus, histidine phosphorylation modulated by NME1 and LHPP may be highly associated with tumorigenesis. Notably, NME1 was first identified as a tumor metastasis suppressor in melanoma (41), which contributes to genome stability by possessing three main enzymatic activities, including nucleoside diphosphate kinase (NDPK), histidine kinase (hisK) and 3'-5'exonuclease (3'-5' EXO) functions $(40,42)$. Thus, the functions of NME1 may potentially differ between tumor types. Investigation of the association between NME1 and LHPP is a key point for future studies.

The phosphatidylinositol-3-kinase/protein kinase B (PI3K/AKT) signaling pathway is one of the most classical pathways involved in tumorigenesis. It is aberrantly activated by extracellular signals, such as the insulin receptor tyrosine kinase (InsR), epidermal growth factor (EGF), the associated insulin-like growth factor 1 receptor (IGF-1R), platelet-derived growth factor receptors (PDGF-R), and plays an extremely important part in regulating cell proliferation and maintaining the biological features of malignant cells $(12,13,16)$. PI3K can generate PIP3 in the plasma membrane, then PIP3 causes the aggregation of AKT by interacting with the $\mathrm{PH}$ domain of AKT (12). Subsequently, an increase in AKT expression or activity becomes the first step for the progression of various types of tumor. For instance, the PI3K/AKT signaling pathway promotes metastasis of CRC (16). Activation of AKT is essential for decreasing apoptosis in breast cancer (17). In addition, PI3K/AKT contributes to drug resistance by inhibiting the expression of p53 in ovarian cancer cells (43). Consistently, the present study observed that the expression levels of p-AKT and p-PI3K were positively decreased by LHPP overexpression in CRC cells. On the contrary, knockdown of LHPP increased p-AKT and p-PI3K expression levels and activity. Furthermore, LHPP-induced $\mathrm{p} 53$ was markedly opposite from the activation of p-AKT and p-PI3K. Thus, it was speculated that LHPP suppresses the activity of the PI3K/AKT signaling pathway to promote p-53 expression, contributing to suppression of cell growth and proliferation.

In conclusion, the present study demonstrated that the expression level of LHPP was deregulated in CRC tissues compared with matched noncancerous tissues, which indicated that LHPP may be a potential tumor suppressor. Further experiments demonstrated that LHPP could inhibit cell growth and proliferation, and promote apoptosis by modulating PI3K/AKT expression and activation. Therefore, the data from the present study may provide reliable and effective evidence towards developing novel CRC therapy options. In addition, the present study investigated the association between LHPP expression and CRC metastasis and apoptosis. Additional potential mechanisms underlying the biological functions of LHPP are currently under research.

\section{Acknowledgements}

Not applicable.

\section{Funding}

This research was supported by grants from the Science and Technology Foundation of Shaanxi Province (S2018-YFZDSF-0102) and the Shaanxi Province Key Scientific and Technological Innovation Team Project (2014KCT-24).

\section{Availability of data and materials}

The data used to support the findings of this study are included within the article.

\section{Authors' contributions}

DC and $\mathrm{BH}$ designed the study. BH, WL, ZL, QZ and XZ performed the experiments. $\mathrm{BH}$ wrote the manuscript. PX, $\mathrm{JL}$ and JM contributed to the experiments, revised and edited the manuscript and revised it critically for important intellectual content. All authors read and approved the manuscript 
and agree to be accountable for all aspects of the research in ensuring that the accuracy or integrity of any part of the work are appropriately investigated and resolved.

\section{Ethics approval and consent to participate}

The present study was approved by the Ethics Committee of The Fifth Affiliated Hospital of Xi'an Jiaotong University and all the participants signed informed consent. The protocol of the present study conformed to the ethical guidelines of the 1975 Declaration of Helsinki (No. XJTU1AF2018LSF-121).

\section{Patient consent for publication}

Not applicable.

\section{Competing interests}

The authors declare that they have no potential competing interests.

\section{Reference}

1. Siegel RL, Miller KD and Jemal A: Cancer statistics, 2019. CA Cancer J Clin 69: 7-34, 2019.

2. Brenner H, Kloor M and Pox CP: Colorectal cancer. Lancet 383: 1490-1502, 2014.

3. Miller KD, Nogueira L, Mariotto AB, Rowland JH, Yabroff KR, Alfano CM, Jemal A, Kramer JL and Siegel RL: Cancer treatment and survivorship statistics, 2019. CA Cancer J Clin 69 363-385, 2019.

4. Sankaranarayanan R, Swaminathan R, Brenner H, Chen K, Chia KS, Chen JG, Law SC, Ahn YO, Xiang YB, Yeole BB, et al: Cancer survival in Africa, Asia, and Central America: A population-based study. Lancet Oncol 11: 165-173, 2010.

5. Brenner H, Bouvier AM, Foschi R, Hackl M, Larsen IK, Lemmens V, Mangone L and Francisci S; EUROCARE Working Group: Progress in colorectal cancer survival in Europe from the late 1980 s to the early 21 st century: The EUROCARE study. Int J Cancer 131: 1649-1658, 2012.

6. Yokoi F, Hiraishi H and Izuhara K: Molecular cloning of a cDNA for the human phospholysine phosphohistidine inorganic pyrophosphate phosphatase. J Biochem 133: 607-614, 2003.

7. Hiraishi H, Ohmagari T, Otsuka Y, Yokoi F and Kumon A: Purification and characterization of hepatic inorganic pyrophosphatase hydrolyzing imidodiphosphate. Arch Biochem Biophys 341: 153-159, 1997.

8. El Sheikh SS, Domin J, Tomtitchong P, Abel P, Stamp G and Lalani EN: Topographical expression of class IA and class II phosphoinositide 3-kinase enzymes in normal human tissues is consistent with a role in differentiation. BMC Clin Pathol 3: 4, 2003.

9. Hindupur SK, Colombi M, Fuhs SR, Matter MS, Guri Y, Adam K, Cornu M, Piscuoglio S, Ng CKY, Betz C, et al: The protein histidine phosphatase LHPP is a tumour suppressor. Nature 555: 678-682, 2018.

10. Hiraishi $H$, Yokoi $F$ and Kumon A: 3-phosphohistidine and 6-phospholysine are substrates of a 56-kDa inorganic pyrophosphatase from bovine liver. Arch Biochem Biophys 349: 381-387, 1998.

11. Zheng J, Dai X, Chen H, Fang C, Chen J and Sun L: Down-regulation of LHPP in cervical cancer influences cell proliferation, metastasis and apoptosis by modulating AKT. Biochem Biophys Res Commun 503: 1108-1114, 2018.

12. Noorolyai S, Shajari N, Baghbani E, Sadreddini S and Baradaran B: The relation between PI3K/AKT signalling pathway and cancer. Gene 698: 120-128, 2019.

13. Bakin AV, Tomlinson AK, Bhowmick NA, Moses HL and Arteaga CL: Phosphatidylinositol 3-kinase function is required for transforming growth factor beta-mediated epithelial to mesenchymal transition and cell migration. J Biol Chem 275: 36803-36810, 2000.

14. $\mathrm{Xu} \mathrm{W}$, Yang $\mathrm{Z}$ and $\mathrm{Lu} \mathrm{N}$ : A new role for the PI3K/Akt signaling pathway in the epithelial-mesenchymal transition. Cell Adhes Migr 9: 317-324, 2015.
15. Bellacosa A,Kumar CC,Di Cristofano A and Testa JR: Activation of AKT kinases in cancer: Implications for therapeutic targeting. Adv Cancer Res 94: 29-86, 2005.

16. Johnson SM, Gulhati P, Rampy BA, Han Y, Rychahou PG, Doan HQ, Weiss HL and Evers BM: Novel expression patterns of PI3K/Akt/mTOR signaling pathway components in colorectal cancer. J Am Coll Surg 210: 767-778, 2010.

17. Campbell IG, Russell SE, Choong DY, Montgomery KG, Ciavarella ML, Hooi CS, Cristiano BE, Pearson RB and Phillips WA: Mutation of the PIK3CA gene in ovarian and breast cancer. Cancer Res 64: 7678-7681, 2004.

18. Samuels Y, Wang Z, Bardelli A, Silliman N, Ptak J, Szabo S, Yan H, Gazdar A, Powell SM, Riggins GJ, et al: High frequency of mutations of the PIK3CA gene in human cancers. Science 304: 554, 2004

19. Bahrami A, Khazaei M, Hasanzadeh M, ShahidSales S, Joudi Mashhad M, Farazestanian M, Sadeghnia HR, Rezayi M, Maftouh M, Hassanian SM and Avan A: Therapeutic potential of targeting PI3K/AKT pathway in treatment of colorectal cancer: Rational and progress. J Cell Biochem 119: 2460-2469, 2018.

20. Wojnar A,Pula B,Piotrowska A, Jethon A, Kujawa K, KobierzyckiC, Rys J, Podhorska-Okolow M and Dziegiel P: Correlation of intensity of MT-I/II expression with Ki-67 and MCM-2 proteins in invasive ductal breast carcinoma. Anticancer Res 31: 3027-3033, 2011.

21. Remmele W and Stegner HE: Recommendation for uniform definition of an immunoreactive score (IRS) for immunohistochemical estrogen receptor detection (ER-ICA) in breast cancer tissue. Pathologe 8: 138-140, 1987 (In German).

22. Arocho A, Chen B, Ladanyi M and Pan Q: Validation of the 2-DeltaDeltaCt calculation as an alternate method of data analysis for quantitative PCR of BCR-ABL P210 transcripts. Diagn Mol Pathol 15: 56-61, 2006.

23. Lv Q, Wang G, Zhang Y, Han X, Li H, Le W, Zhang M, Ma C, Wang P and Ding Q: FABP5 regulates the proliferation of clear cell renal cell carcinoma cells via the PI3K/AKT signaling pathway. Int J Oncol 54: 1221-1232, 2019.

24. Euhus DM, Hudd C, LaRegina MC and Johnson FE: Tumor measurement in the nude mouse. J Surg Oncol 31: 229-234, 1986.

25. Wallace J: Humane endpoints and cancer research. ILAR J 41: 87-93, 2000.

26. Workman P, Aboagye EO, Balkwill F, Balmain A, Bruder G, Chaplin DJ, Double JA, Everitt J, Farningham DA, Glennie MJ, et al: Committee of the National Cancer Research Institute: Guidelines for the welfare and use of animals in cancer research. Br J Cancer 102: 1555-1577, 2010.

27. Forbes D, Blom HJM, Kostomitsopoulos N, Moore G and Perretta G: FELASA EUROGUIDE. On the accomodation and care of animals used for experimental and other scientific purposes. The Royal Society of Medicine Press Ltd., 2007.

28. Panda S, Srivastava S, Li Z, Vaeth M, Fuhs SR, Hunter T and Skolnik EY: Identification of PGAM5 as a mammalian protein histidine phosphatase that plays a central role to negatively regulate CD4(+) T cells. Mol Cell 63: 457-469, 2016.

29. Klumpp S, Hermesmeier J, Selke D, Baumeister R, Kellner R and Krieglstein J: Protein histidine phosphatase: A novel enzyme with potency for neuronal signaling. J Cereb Blood Flow Metab 22: 1420-1424, 2002.

30. Kudo Y, Kitajima S, Ogawa I, Miyauchi M and Takata T: Down-regulation of Cdk inhibitor p27 in oral squamous cell carcinoma. Oral Oncol 41: 105-116, 2005.

31. Peurala E, Koivunen P, Haapasaari KM, Bloigu R and Jukkola-Vuorinen A: The prognostic significance and value of cyclin D1, CDK4 and p16 in human breast cancer. Breast Cancer Res 15: R5, 2013.

32. Wang H, Chen X, Chen Y, Sun L, Li G, Zhai M, Zhai W, Kang Q, Gao Y and Qi Y: Antitumor activity of novel chimeric peptides derived from cyclinD/CDK4 and the protein transduction domain 4. Amino Acids 44: 499-510, 2013.

33. Juríková M, Danihel L', Polák Š and Varga I: Ki67, PCNA, and MCM proteins: Markers of proliferation in the diagnosis of breast cancer. Acta Histochem 118: 544-552, 2016.

34. Celis JE and Celis A: Cell cycle-dependent variations in the distribution of the nuclear protein cyclin proliferating cell nuclear antigen in cultured cells: Subdivision of S phase. Proc Natl Acad Sci USA 82: 3262-3266, 1985.

35. Prelich G and Stillman B: Coordinated leading and lagging strand synthesis during SV40 DNA replication in vitro requires PCNA. Cell 53: 117-126, 1988.

36. Wang X, Simpson ER and Brown KA: p53: Protection against tumor growth beyond effects on cell cycle and apoptosis. Cancer Res 75: 5001-5007, 2015. 
37. Stewart ZA and Pietenpol JA: p53 Signaling and cell cycle checkpoints. Chem Res Toxicol 14: 243-263, 2001.

38. Waldman T, Kinzler KW and Vogelstein B: p21 is necessary for the p53-mediated G1 arrest in human cancer cells. Cancer Res 55: 5187-5190, 1995.

39. Fuhs SR, Meisenhelder J, Aslanian A, Ma L, Zagorska A, Stankova M, Binnie A, Al-Obeidi F, Mauger J, Lemke G, et al: Monoclonal 1- and 3-phosphohistidine antibodies: New tools to study histidine phosphorylation. Cell 162: 198-210, 2015.

40. Hartsough MT, Morrison DK, Salerno M, Palmieri D, Ouatas T, Mair M, Patrick J and Steeg PS: Nm23-H1 metastasis suppressor phosphorylation of kinase suppressor of Ras via a histidine protein kinase pathway. J Biol Chem 277: 32389-32399, 2002.

41. Leonard MK, Novak M, Snyder D, Snow G, Pamidimukkala N McCorkle JR, Yang XH and Kaetzel DM: The metastasis suppressor NME1 inhibits melanoma cell motility via direct transcriptional induction of the integrin beta-3 gene. Exp Cell Res 374: 85-93, 2019.
42. Freije JM, Blay P, MacDonald NJ, Manrow RE and Steeg PS: Site-directed mutation of Nm23-H1. Mutations lacking motility suppressive capacity upon transfection are deficient in histidine-dependent protein phosphotransferase pathways in vitro. J Biol Chem 272: 5525-5532, 1997.

43. Guo SL, Ye H, Teng Y, Wang YL, Yang G, Li XB, Zhang C, Yang $X$, Yang ZZ and Yang X: Akt-p53-miR-365-cyclin D1/cdc25A axis contributes to gastric tumorigenesis induced by PTEN deficiency. Nat Commun 4: 2544, 2013.

This work is licensed under a Creative Commons Attribution-NonCommercial-NoDerivatives 4.0 International (CC BY-NC-ND 4.0) License. 